\title{
Preparation and Properties of Siloxane/Epoxy Organic-Inorganic Hybrid Thin Films, Self-Standing Films, and Bulk Bodies
}

\author{
By Takahiro GUNJI, ${ }^{1, *}$ Shotaro ITAGAKI, ${ }^{1}$ Takashi KAJIWARA, ${ }^{1}$ \\ Yoshimoto ABE, ${ }^{1}$ Tadashi HATAKEYAMA, ${ }^{2}$ and Ryuichi AOKI ${ }^{2}$
}

Polysiloxanes such as poly-APS and poly-EPS were prepared by the hydrolytic polycondensation of 3-aminopropyl(trimethoxy)silane (APS) and 3- $N$-2-aminoethylaminopropyl(trimethoxy)silane (EPS) in the nitrogen stream, respectively. PolyAPS or poly-EPS was mixed with bisphenol-A diglycidyl ether (828EL) in methyl ethyl ketone or dichloromethane, and the mixture was subjected to heating to prepare transparent and homogeneous thin films. A coating film was prepared by spincoating on glass and heating to give a pencil hardness of $9 \mathrm{H}$ when equivalent mixing was achieved. This hardness value is greater than that obtained using ethylenediamine in place of poly-APS or poly-EPS. The three-point-bending test was applied to the bulk bodies to show a maximum Young's modulus of 199.1 MPa for poly-APS and 322.6 MPa for poly-EPS when equivalent mixing was achieved.

KEY WORDS: 3-Aminopropyl(trimethoxy)silane / 3-N-2-Aminoethylaminopropyl(trimethoxy)silane / Bisphenol A Diglycidyl Ether /

Organic-Inorganic Hybrid / Self-Standing Film /

Study of the preparation and application of organic/ inorganic hybrids is an area of great interest, as these hybrids are expected to have novel functions and applications that are not possible when using only organics or inorganics. ${ }^{1}$ The organic/inorganic hybrids are classified based on their mixing and connections: ${ }^{2}$ (1) dispersion type, (2) interpenetrating type, and (3) molecular hybrid type. In hybrids of (1) the dispersion type, inorganic materials are dispersed in organic polymers, ${ }^{3-5}$ or organic materials are dispersed in inorganic polymers. ${ }^{6}$ Because the organic and inorganic components in this type of hybrid are phase-separated, a homogeneous mixture of organic/inorganic hybrid materials is prepared by applying molecular interactions between organic and inorganic components such as hydrogen bonding and $\pi-\pi$ interactions. In hybrids of (2) the interpenetrating type, organic and inorganic polymer chains form a penetrating structure by polymerization of organic components in the inorganic components. ${ }^{7-10}$ The hybrids of (3) molecular hybrids are characterized by the formation of covalent bonding between organic and inorganic components, which provides highly homogeneous hybrids by hybridization of organic and inorganic components in angstrom level. We have prepared molecular hybrids from 3-methacryloxypropyl(trimethoxy)silane ${ }^{11,12}$ and trimethoxy(vinyl)silane ${ }^{13}$ and characterized them based on the structure and molecular weight of the organic and inorganic components.

Epoxy resins are widely used as adhesives and paints because they have high hardness and heat-resistivity. In addition, the hybrid materials of epoxy resins and silica have been studied, including polymers with high strength, ${ }^{14}$ adhesives for metal and plastics, ${ }^{15}$ gas separation film with high selectivity, ${ }^{16}$ and biomaterials ${ }^{17}$ starting from 3 - $N$-2-aminoethylaminopropyl(trimethoy)silane (EPS).
In this study, the reactions of polysiloxanes having amino groups on their side chains with epoxy resins were investigated with regard to preparing and evaluating organic/inorganic hybrids of the molecular hybrid type to apply as a top-coat painting. The application of epoxy-resins as top-coatings often comes to an obstacle due to coloring in brown. The coloring is expected to be avoided by the reaction conditions. In contrast, the hardness of painting films would be appeared by both siloxane network and epoxy-resins. In this study, therefore, we designed a method for the formation of covalent bonding between epoxy-resins and polysiloxanes by in situ polymerization, which will provide a convenient and wide application of polymer hybrids. The preparation and characterization of self-standing films, bulk bodies, and coating films were investigated according to the equations (1) and (2) in Scheme 1.

\section{EXPERIMENTAL}

\section{Reagents}

3-Aminopropyl(trimethoxy)silane (APS), EPS, ethylene diamine (EDA), triethylamine, methanol, ethanol, tetrahydrofuran, hexane, acetone, dichloromethane, chloroform, diethyl ether, toluene, methyl ethyl ketone (MEK), and acetonitrile (Kanto Chemical) were used as purchased. Acetic anhydride (Wako Pure Chemical Industries, Ltd.) was used as purchased. Bisphenol-A diglycidyl ether (828EL) (Japan Epoxy Resin) was also used as purchased.

\section{Preparation of Poly-APS and Poly-EPS}

Into a 200-mL four-necked flask equipped with a nitrogen inlet and outlet tubes, APS $35.86 \mathrm{~g}(0.20 \mathrm{~mol})$ and methanol

\footnotetext{
${ }^{1}$ Department of Pure and Applied Chemistry, Faculty of Science and Technology, Tokyo University of Science, 2641 Yamazaki, Noda 278-8510, Japan ${ }^{2}$ R\&D Center, Dai Nippon Toryo Co., Ltd. 1382-12 Shimoishigami, Ohtawara 324-8516, Japan

*To whom correspondence should be addressed (Tel: +81-4-7122-9499, Fax: +81-4-7123-9890, E-mail: gunji@rsnodatus.ac.jp).
} 

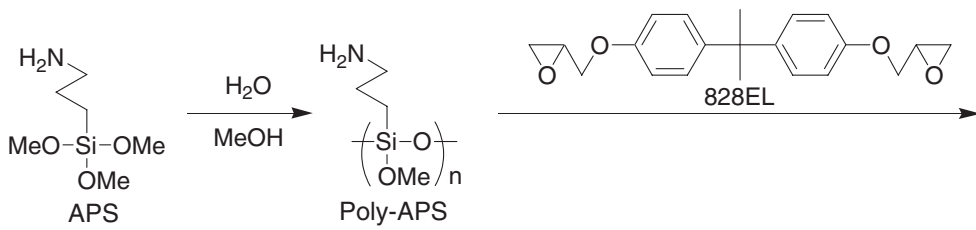

Poly-APS

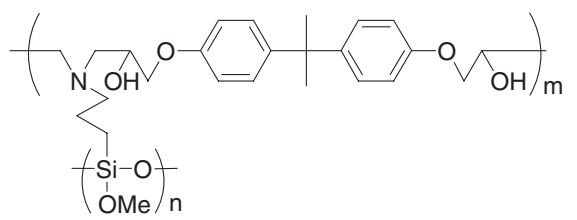

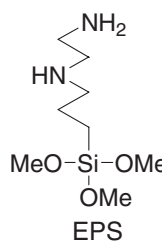
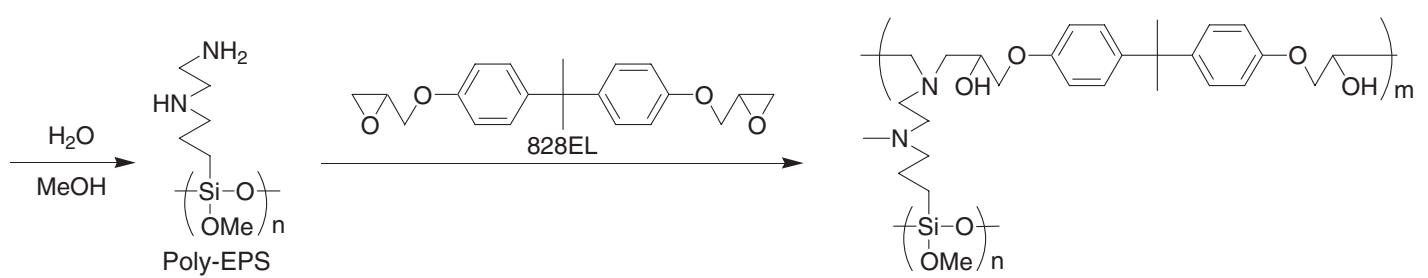

Scheme 1. Schemes for the preparation of siloxane/epoxy hybrids.

$13.25 \mathrm{~g}(0.41 \mathrm{~mol})$ were charged and cooled with an ice-bath for $10 \mathrm{~min}$. Nitrogen was introduced at a rate of $360 \mathrm{~mL} / \mathrm{min}$, and water was then added in a dropwise manner, followed by stirring for $10 \mathrm{~min}$. After stirring for $10 \mathrm{~min}$ at room temperature, stirring was continued for $3 \mathrm{~h}$ at $70^{\circ} \mathrm{C}$ to obtain a colorless viscous liquid or colorless gel.

Poly-EPS was prepared using the same procedure by starting from EPS $44.48 \mathrm{~g}(0.20 \mathrm{~mol})$.

\section{Preparation of $\boldsymbol{N}$-Acetyl Poly-APS and $\boldsymbol{N}$-Acetyl Poly-EPS}

Poly-APS $1.20 \mathrm{~g}$, methanol $15 \mathrm{~mL}$, and triethylamine 6.23 $\mathrm{mL}$ were mixed and cooled by ice bath. Acetic anhydride $2.85 \mathrm{~mL}$ was added dropwisely into this mixture. After stirring for $1 \mathrm{~h}$, the solvents were removed under reduced pressure to give $N$-acetyl poly-APS.

Poly-EPS $1.65 \mathrm{~g}$, methanol $15 \mathrm{~mL}$, and triethylamine $9.34 \mathrm{~mL}$ were mixed and cooled by ice bath. Acetic anhydride $4.26 \mathrm{~mL}$ was added dropwisely into this mixture. After stirring for $1 \mathrm{~h}$, the solvents were removed under reduced pressure to give $N$-acetyl poly-APS.

Preparation of Poly-APS/828EL and Poly-EPS/828EL Self-Standing Films, Coating Films, and Bulk Bodies

828EL $5.1 \mathrm{~g}(0.015 \mathrm{~mol})$ was charged into a $20-\mathrm{mL}$ vial, and APS or Poly-APS was added to establish the molar amount of amino groups at $0.015 \mathrm{~mol}$; solvent was then added to prepare 80,50 , or $20 \mathrm{wt} \%$ solution. $5 \mathrm{~g}$ of this solution was poured into a sharle made from polymethylpentene and then allowed to rest at room temperature for $12 \mathrm{~h}$. A selfstanding film was obtained by a subsequent heating at $80^{\circ} \mathrm{C}$ for $12 \mathrm{~h}$.

828EL $5.1 \mathrm{~g}(0.015 \mathrm{~mol})$ was charged into a $20-\mathrm{mL}$ vial; APS or Poly-APS was added, and MEK was then added to prepare a $50 \mathrm{wt} \%$ solution. After stirring for $1.5 \mathrm{~h}$ at room temperature, this solution was subjected to spin-coating on a slide glass at $1500 \mathrm{rpm}$ for $30 \mathrm{~s}$. A coating film was obtained by subsequent heating at $80^{\circ} \mathrm{C}$ for $12 \mathrm{~h}$.
828EL $5.1 \mathrm{~g}(0.015 \mathrm{~mol})$ was charged into a $20-\mathrm{mL}$ vial. APS or Poly-APS was added, and then MEK was added to prepare a $50 \mathrm{wt} \%$ solution. After stirring for $1.5 \mathrm{~h}$ at room temperature, this solution was poured into a sharle made from polymethylpentene and then allowed to rest at room temperature for $12 \mathrm{~h}$. After cutting this material to a size of $10 \mathrm{~mm}$ wide and $30 \mathrm{~mm}$ length, this sample was covered with polymethylpentene plates, pressed by pinching, and then subjected to heating at $80^{\circ} \mathrm{C}$ for $12 \mathrm{~h}$ to provide a bulk body.

Self-standing films, coating films, and bulk bodies using EPS or Poly-EPS were prepared by the same procedure described above.

\section{Measurement and Analysis}

Fourier-transformation infrared absorption (FT-IR) spectra were obtained by JASCO FT/IR-6100.

${ }^{1} \mathrm{H}$ and ${ }^{29} \mathrm{Si}$ Fourier-transformed nuclear magnetic resonance (NMR) spectra were obtained by JEOL ECP-300. Methanol- $d_{4}$ was used as a solvent.

The gel permeation chromatography (GPC) was performed using Shimadzu LC system LC-10 equipped with a refractive index detector. Two polystyrene columns (Asahipak Column GF-7M HQ and GF-510 HQ) were connected directly. Methanol was used as an eluent. Polyvinyl alcohol was used as a standard for molecular weight calculation.

Thermogravimetric/differential thermal analysis (TG-DTA) was recorded using Mac Science TG-DTA 2020S under air atmosphere. The heating rate was $10^{\circ} \mathrm{C} / \mathrm{min}$.

The mechanical property, three-point vending test, was carried out using Orientec Tensilon/UTM-II-20. The width between the two edges was $20 \mathrm{~mm}$.

Pencil hardness was evaluated based on the Japanese Industrial Standard JIS-K5400 using a Yausda Seiki pencil hardness tester. Pencils Uni ${ }^{\mathrm{TM}}$ fabricated by Mitsubishi Pencil were used. The hardness was ordered as $6 \mathrm{~B}$ (softest), 5B, 4B, $3 \mathrm{~B}, 2 \mathrm{~B}, \mathrm{~B}, \mathrm{HB}, \mathrm{F}, \mathrm{H}, 2 \mathrm{H}, 3 \mathrm{H}, 4 \mathrm{H}, 5 \mathrm{H}, 6 \mathrm{H}, 7 \mathrm{H}, 8 \mathrm{H}$, and $9 \mathrm{H}$ (hardest). 
Table I. Result of the synthesis of Poly-APS ${ }^{a}$ and Poly-EPS

\begin{tabular}{ccccc}
\hline No. & Sample & $\begin{array}{c}\mathrm{H}_{2} \text { O/APS or EPS } \\
\text { Molar ratio }\end{array}$ & Yield/g & State \\
\hline 1 & Poly-APS & 1.25 & 24.7 & Highly viscous liquid \\
2 & & 1.50 & 24.4 & Highly viscous liquid \\
3 & & 1.55 & 24.2 & Gel \\
\hline 4 & Poly-EPS & 1.25 & 32.8 & Viscous liquid \\
5 & & 1.50 & 31.8 & Highly viscous liquid \\
6 & & 1.55 & 30.6 & Gel \\
\hline
\end{tabular}

ascale in operation: APS $35.86 \mathrm{~g}(0.20 \mathrm{~mol}), \mathrm{MeOH} 13.25 \mathrm{~g}(0.41 \mathrm{~mol})$, $\mathrm{H}_{2} \mathrm{O} 4.5-5.58 \mathrm{~g}(0.25-0.31 \mathrm{~mol})$. Temp.: $70^{\circ} \mathrm{C}$. Time: $3 \mathrm{~h}$. Rate of nitrogen introduced: $360 \mathrm{~mL} / \mathrm{min}$. ' ${ }^{2}$ Scale in operation: EPS $44.48 \mathrm{~g}(0.20 \mathrm{~mol})$, $\mathrm{MeOH} 13.25 \mathrm{~g}(0.41 \mathrm{~mol}), \mathrm{H}_{2} \mathrm{O} 4.5-5.58 \mathrm{~g}(0.25-0.31 \mathrm{~mol})$. Temp.: $70^{\circ} \mathrm{C}$. Time: $3 \mathrm{~h}$. Rate of nitrogen introduced: $360 \mathrm{~mL} / \mathrm{min}$

\section{RESULTS AND DISCUSSION}

\section{Results of the Synthesis of Poly-APS and Poly-EPS}

The results for poly-APS and poly-EPS are summarized in Table I. Poly-APS was synthesized by the hydrolytic condensation of APS by using water in the molar ratio of $\mathrm{H}_{2} \mathrm{O}$ / APS $=1.25,1.50$, and 1.55. The yield of Poly-APS decreased with the increasing molar ratio of water, which suggests the presence of further hydrolytic condensation. Poly-APS was highly viscous liquid in No. 1 and 2, while gel was formed in No. 3. Poly-APS (No. 1 and 2) was soluble in water, methanol, ethanol, acetone, MEK, dichloromethane, and chloroform, while the solubility of poly-APS (No. 2) was decreased in MEK.

Poly-EPS was synthesized by the same procedure. The molar ratio of water to EPS was $\mathrm{H}_{2} \mathrm{O} / \mathrm{EPS}=1.25,1.50$, and 1.55. Poly-EPS was a viscous liquid (No. 4), highly viscous liquid (No. 5), and gel (No. 6). Poly-EPS (No. 5) was soluble in water, methanol, ethanol, acetone, MEK, dichloromethane, chloroform, and toluene.

The ${ }^{1} \mathrm{H}$ NMR spectrum of poly-EPS (No. 5) showed signals at $0.61 \mathrm{ppm}\left(\mathrm{CH}_{2}\right.$ in $\left.\mathrm{SiCH}_{2} \mathrm{CH}_{2}\right), \quad 1.57 \mathrm{ppm}\left(\mathrm{CH}_{2}\right.$ in $\left.\mathrm{SiCH}_{2} \mathrm{CH}_{2}\right)$, $2.59 \mathrm{ppm}\left(\mathrm{CH}_{2}\right.$ in $\left.\mathrm{CH}_{2} \mathrm{CH}_{2} \mathrm{NHCH}_{2} \mathrm{CH}_{2} \mathrm{NH}_{2}\right)$, $2.73 \mathrm{ppm}\left(\mathrm{CH}_{2}\right.$ in $\left.\mathrm{NHCH}_{2} \mathrm{CH}_{2} \mathrm{NH}_{2}\right), 3.32 \mathrm{ppm}\left(\mathrm{SiOCH}_{3}\right)$, and $4.69 \mathrm{ppm}\left(\mathrm{NH}\right.$ and $\left.\mathrm{NH}_{2}\right)$.

A ${ }^{29} \mathrm{Si} \mathrm{NMR}$ spectrum of poly-EPS (No. 5) is shown in Figure 1. In the spectrum of poly-EPS, a signal ascribed to $T^{0}$ disappeared, while signals of $T^{1}, T^{2}$, and $T^{3}$ were observed at $-49.4--50.3 \mathrm{ppm}, \quad-55.2--61.2 \mathrm{ppm}$, and $-63.1--71.2 \mathrm{ppm}$, respectively. ( $T^{n}$ denotes a structure $\mathrm{Si}(\mathrm{OSi})_{n}(\mathrm{OMe})_{3-n}(n=0-3)$.) The ratio of each peak area was calculated as $3 \%\left(T^{1}\right), 17 \%\left(T^{1}\right), 80 \%\left(T^{1}\right)$, respectively. The percentage of siloxane bonding was calculated as $92 \%$, according to the equation $\sum_{n}^{0-3}\left(n \times T^{n} / 3\right)(\%)$.

In order to estimate the molecular weight of poly-APS or poly-EPS, these polymers were acetylated by using acetic anhydride. The percentage of acetylated amino proton was calculated by means of the proton ratio of acetyl group against methylene protons in ${ }^{1} \mathrm{H}$ NMR spectrum to be $52 \%$ (No. 1), $53 \%$ (No. 2), $36 \%$ (No. 4), and 40\% (No. 5). The molecular weights of these $N$-acecyl poly-APS and $N$-acetyl poly-EPS

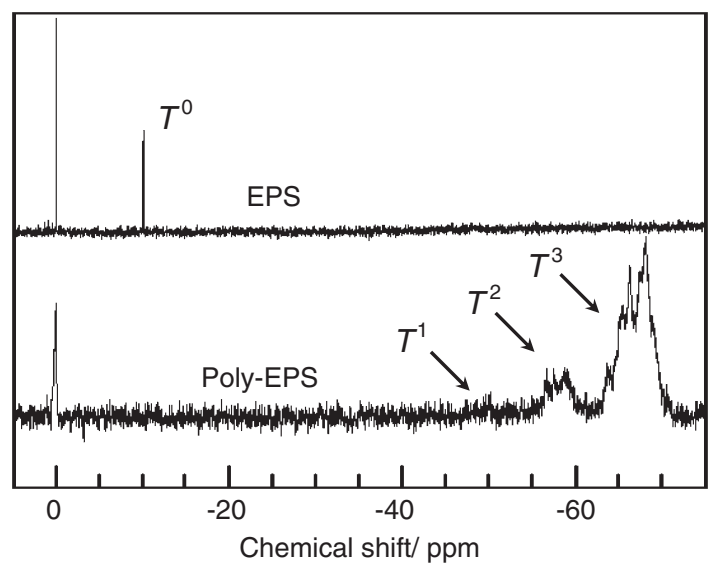

Figure 1. ${ }^{29}$ Si NMR spectra of EPS \& Poly-EPS.

Table II. Result of the preparation of self-standing films ${ }^{a}$

\begin{tabular}{cccc}
\hline \multirow{2}{*}{ Solvent } & \multirow{2}{*}{ Concentration/wt \% } & \multicolumn{2}{c}{ State of self-standing films } \\
\cline { 3 - 4 } & & Poly-APS (No. 2) & Poly-EPS (No. 5) \\
\hline Methanol & 50 & Opaque & Opaque \\
\hline Toluene & 50 & Opaque & Opaque \\
\hline \multirow{2}{*}{ MEK } & 80 & Transparent & Transparent \\
& 50 & Transparent & Transparent \\
& 20 & Transparent & Transparent \\
\hline \multirow{2}{*}{ Dichloromethane } & 80 & Transparent & Transparent \\
& 50 & Transparent & Transparent \\
& 20 & Transparent & Transparent \\
\hline
\end{tabular}

${ }^{\mathrm{a}} \mathrm{A}$ solution was poured into a polymethylpentane sharle and aged at room temperature for $12 \mathrm{~h}$ and $80^{\circ} \mathrm{C}$ for $12 \mathrm{~h}$. ${ }^{\mathrm{b}}$ Colored in brown.

were $46000\left(M_{\mathrm{w}} / M_{\mathrm{n}}=1.33\right.$, No. 1$), 42000\left(M_{\mathrm{w}} / M_{\mathrm{n}}=1.23\right.$, No. 2), $34000\left(M_{\mathrm{w}} / M_{\mathrm{n}}=1.16\right.$, No. 4), and $75000\left(M_{\mathrm{w}} / M_{\mathrm{n}}=\right.$ 1.62 , No. 5). The molecular weight of poly-APS and poly-EPS were calculated as 33000 (No. 1), 31000 (No. 2), 27000 (No. 4), and 59000 (No. 5).

Results of the Preparation of Poly-APS/828EL and PolyEPS/828EL Self-Standing Films

The results of the preparation of self-standing films from poly-APS (No. 2) and poly-EPS (No. 5) are summarized in Table II. Photographs of self-standing films from poly-EPS (No. 5) are shown in Figure 2. These self-standing films were prepared by heating a methanol, toluene, MEK, or dichloromethane solution of poly-EPS (No. 5) at $80^{\circ} \mathrm{C}$. Translucent and phase-separated poly-EPS/828EL self-standing films were prepared when methanol or toluene solution was used. On the other hand, transparent and homogeneous poly-EPS/828EL self-standing films were obtained from MEK or dichloromethane solution. The phase separation in poly-EPS/828EL self-standing films is based on the differences in solubility of epoxy and polysiloxane components, which is depressed by using good solvents such as MEK or dichloromethane.

Figure 3 shows IR spectra of poly-EPS/828EL self-standing films, which were prepared from $50 \mathrm{wt} \%$ MEK solution. An 


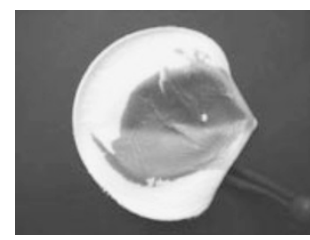

$\mathrm{MeOH}$

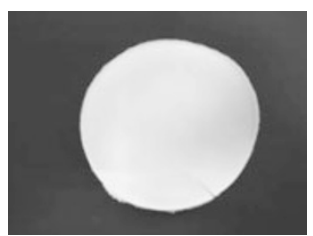

Toluene

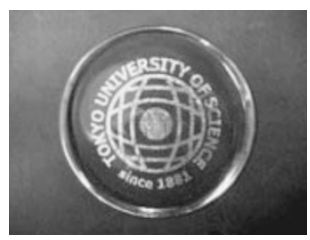

MEK

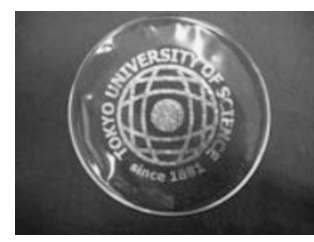

Dichloromethane

Figure 2. Photographs of the Poly-EPS/828EL self-standing films.

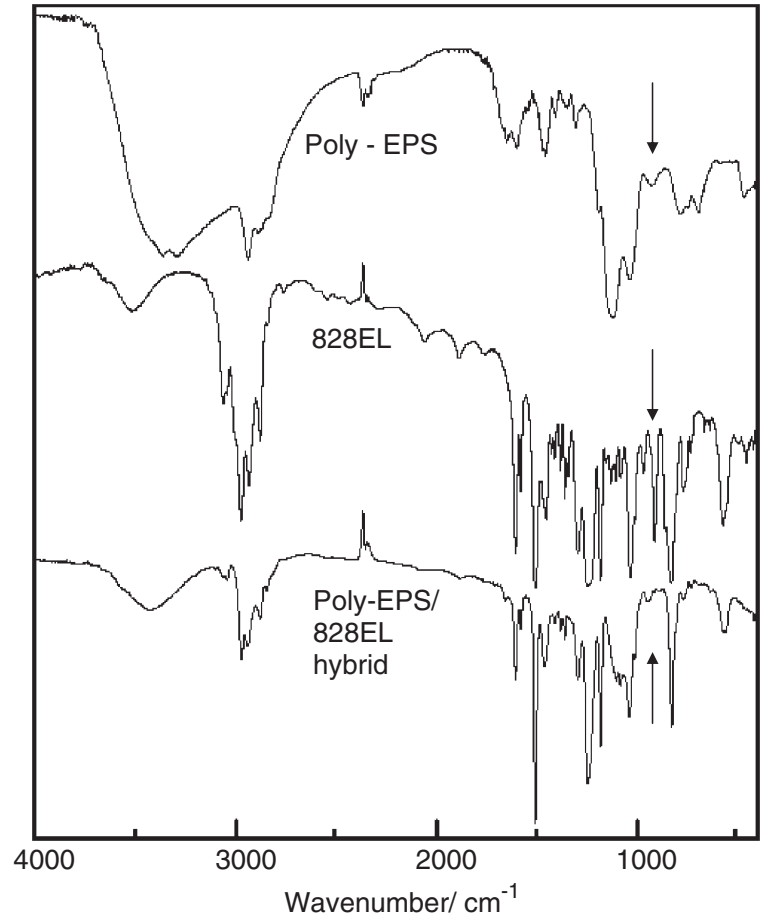

Figure 3. IR spectra of Poly-EPS, 828EL, and Poly-EPS/828EL hybrid.

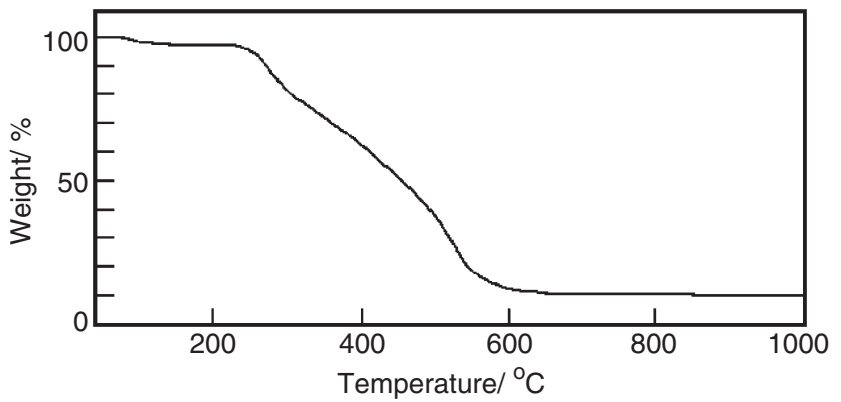

Figure 4. Thermogravimetric trace of Poly-EPS/828EL self-standing film.

absorption peak can be observed at $915 \mathrm{~cm}^{-1}$, which is due to the epoxy group for $828 \mathrm{EL}$, which decreased in size in the spectrum of poly-EPS/828EL hybrid due to ring-opening of the epoxy group to prepare organic-inorganic hybrid.

Thermogravimetric trace of poly-EPS/828EL self-standing films is shown in Figure 4, which shows weight losses at 215$450{ }^{\circ} \mathrm{C}$ and $460-600^{\circ} \mathrm{C}$. The decomposition temperature was

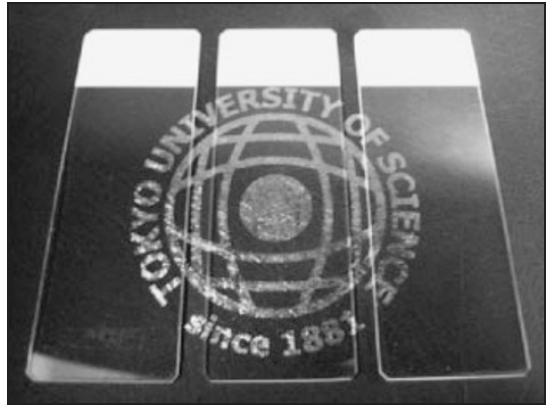

EDA EPS Poly-EPS

Figure 5. EDA/828EL, EPS, and Poly-EPS/828EL thin films.

the same as that of $828 \mathrm{EL}$, and the heat-resistivity of organicinorganic hybrids proved to be primarily affected by $828 \mathrm{EL}$.

\section{Results of the Preparation of Spin-Coating Films}

Figure 5 shows a photograph of thin films prepared by spincoating on a glass plate. Transparent thin films with the thickness of over $1 \mu \mathrm{m}$ were prepared by using EDA, EPS, or poly-EPS.

The pencil hardness of spin-coated films is summarized in Table III. These films were prepared by changing the molar ratio of amino and imino groups in EDA, APS, EPS, poly-APS, or poly-EPS against the epoxy group. When EDA was used, the pencil hardnesses were $\mathrm{B}$ (molar ratio: 50:50), $2 \mathrm{H}$ (molar ratio: 33:67), and $<6 \mathrm{~B}$ (molar ratio: 25:75). The pencil hardness reached a maximum when equivalent mixing was achieved. When the coating films were prepared equivalent mixing, the coating films became harder in the order of EDA, APS, and EPS for the following reasons: a siloxane network was formed in parallel to the reaction of the epoxy group to provide organic-inorganic hybrids. A harder and denser organic network was formed for EPS compared to APS because EPS has more active hydrogen atoms in the molecule than APS.

The decrease in pencil-hardness was relatively small when an excess amount of $828 \mathrm{EL}$ was used compared to APS or poly-APS. This small decrease was due to the relatively slow increase in steric hindrance around the active hydrogen atoms in the amino group for APS and poly-APS compared to EDA, EPS, or poly-EPS.

The mixing of the siloxane network is clear when the pencilhardness between APS and poly-APS or EPS and poly-EPS is compared. In both cases, the reaction of polysiloxane with 
Table III. Pencil-hardness of the coating films ${ }^{a}$

\begin{tabular}{ccc}
\hline Sample & Molar ratio & Pencil-hardness $^{\mathrm{b}}$ \\
\hline EDA/828EL & $50: 50$ & $\mathrm{~B}$ \\
& $33: 67$ & $2 \mathrm{H}$ \\
& $25: 75$ & $6 \mathrm{~B}>$ \\
\hline APS/828EL & $60: 40$ & $\mathrm{H}$ \\
& $50: 50$ & $3 \mathrm{H}$ \\
EPS/828EL & $40: 60$ & $2 \mathrm{H}$ \\
\hline Poly-APS/828EL & $50: 50$ & $\mathrm{HB}$ \\
& $40: 60$ & $9 \mathrm{H}$ \\
& $30: 70$ & $2 \mathrm{~B}$ \\
\hline Poly-EPS/828EL & $60: 40^{c}$ & $4 \mathrm{H}$ \\
& $50: 50^{c}$ & $7 \mathrm{H}$ \\
& $40: 60^{c}$ & $6 \mathrm{H}$ \\
\hline & $50: 50^{c}$ & $3 \mathrm{H}$ \\
& $40: 60^{c}$ & $>9 \mathrm{H}$ \\
& $30: 70^{c}$ & $3 \mathrm{H}$ \\
\hline
\end{tabular}

${ }^{a}$ Aging condition: room temp., $12 \mathrm{~h}$. ${ }^{\mathrm{b}}$ Order of hardness: (soft)

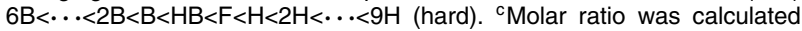
based on the monomer unit in Poly-APS or Poly-EPS.

828EL provided a harder coating film compared to the reaction of silane monomer with $828 \mathrm{EL}$. We can prepare an organicinorganic hybrid, which fully reflects the hardness of the siloxane network, by using a macromolecular in which siloxane bonding is formed in advance. The combination of organic polymers with polysiloxanes offers an organic-inorganic hybrids, which fully reflects the hardness of the siloxane network.

\section{Results of the Preparation of Bulk Bodies}

Bulk bodies were prepared by heating a mixture of EDA, APS, EPS, poly-APS, or poly-EPS with $828 \mathrm{EL}$ in a polymethylpentene sharle. Since the bulk bodies warped on heating, they were cut into small pieces $(10 \mathrm{~mm}$ width, $30 \mathrm{~mm}$ length, $1 \mathrm{~mm}$ thickness), pressed by pinching, and then subjected to heating.

Table IV summarizes the results of the three-point-bending test. When EDA was used, the Young's modulus showed a maximum under the condition of equivalent mixing. When APS or EPS was used, the Young's moduli were smaller than that of EDA because of the insufficient formation of a siloxane network and its interference with the formation of epoxy resin. In contrast, epoxy/polysiloxane hybrids with a full reflection of the networks of these compounds were formed by using polyAPS or poly-EPS because siloxane networks have already been formed in advance of the mixing.

The formation of a dense and highly branched epoxy resin is expected for EDA, EPS, or poly-EPS because these compounds have two amino groups or one amino and one imino group in a molecular unit. When EDA, EPS, or poly-EPS were used, the Young's moduli showed a maximum under the condition of equivalent mixing. In contrast, when APS and poly-APS were used, the Young's moduli increased with increasing amounts of amino groups because many amino groups are required to give a highly branched epoxy resin.
Table IV. Three-point bending test of the bulk bodies ${ }^{\mathrm{a}}$

\begin{tabular}{ccc}
\hline Sample & Molar ratio & Young's modulus/MPa \\
\hline EDA/828EL & $50: 50$ & 203.3 \\
& $33: 66$ & 223.1 \\
& $25: 75$ & 143.8 \\
\hline APS/828EL & $60: 40$ & 184.7 \\
& $50: 50$ & 174.9 \\
EPS/828EL & $40: 60$ & 233.5 \\
\hline Poly-APS/828EL & $50: 50$ & 138.2 \\
& $40: 60$ & 199.1 \\
& $30: 70$ & 189.3 \\
\hline Poly-EPS/828EL & $60: 40^{\mathrm{b}}$ & $-{ }^{\mathrm{c}}$ \\
& $50: 50^{\mathrm{b}}$ & 178.7 \\
& $40: 60^{\mathrm{b}}$ & 273.4 \\
\hline & $50: 50^{\mathrm{b}}$ & 146.1 \\
& $40: 60^{\mathrm{b}}$ & 322.6 \\
& $30: 70^{\mathrm{b}}$ & 263.1 \\
\hline
\end{tabular}

aTesting rate: $5 \mathrm{~mm} / \mathrm{min}$. ${ }^{\mathrm{b}}$ Molar ratio was calculated based on the

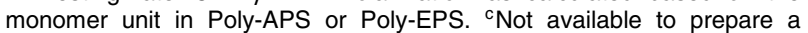
sample.

\section{CONCLUSION}

Polysiloxanes such as poly-APS and poly-EPS with solubility in organic solvents were prepared by the hydrolytic polycondensation of 3-aminopropyl(trimethoxy)silane (APS) and 3-N-2-aminoethylaminopropyl(trimethoxy)silane (EPS) in a nitrogen stream, respectively. Poly-APS and poly-EPS were found to be soluble in water and methanol. These compounds were mixed with bisphenol-A diglycidyl ether (828EL) in methyl ethyl ketone or dichloromethane, and the mixture was subjected to heating to prepare transparent and homogeneous thin films. A coating film was prepared by spin-coating on glass and heating to a pencil hardness of $9 \mathrm{H}$ when equivalent mixing was achieved. The three-point-bending test was applied for the bulk bodies by using EPS or poly-EPS to show the maximum Young's modulus when equivalent mixing was achieved.

\section{Received: November 11, 2008 \\ Accepted: March 30, 2009 \\ Published: May 20, 2009}

\section{REFERENCES}

1. D. A. Loy, MRS Bull., 26, 364 (2001).

2. K. Arimitsu, T. Gunji, and Y. Abe, Chem. Eng., 46, 38 (2001).

3. D. Avnir, D. Levy, and R. Reisfeld, J. Phys. Chem., 88, 5956 (1984).

4. F. Bentinegna, M. Canva, and A. Brun, J. Sol-Gel Sci. Technol., 9, 33 (1997).

5. Y. Kurokawa, Kagaku Kogyo, 40, 937 (1989).

6. L. Spanhel, H. Schmidt, A. Uhrig, and C. Klingshirn, Mater. Res. Soc. Symp. Proc., 272, 53 (1992).

7. L. Spanhel, E. Arpac, and H. Schmidt, J. Non-Cryst. Solids, 147-148, 657 (1992).

8. E. J. A. Pore and J. D. Mackenzie, Mater. Res. Soc. Symp. Proc., 73 809 (1986).

9. J. L. Nogues, S. Majewski, J. K. Walker, M. Bowen, R. Wojck, and W. V. Morehead, J. Am. Ceram. Soc., 71, 1159 (1988).

10. E. J. A. Pore, in "Sol-Gel Optics II (SPIE Proceedings)," J. D. 
Mackenzie, Ed., SPIE, Bellingham, WA, 1992, Vol. 1758, p 360.

11. Y. Abe, Y. Honda, and T. Gunji, Appl. Organomet. Chem., 12, 749 (1998).

12. T. Gunji, Y. Makabe, N. Takamura, and Y. Abe, Appl. Organomet. Chem., 15, 683 (2001).

13. T. Gunji, M. Okonogi, T. Sakan, N. Takamura, K. Arimitsu, and Y. Abe, Appl. Organomet. Chem., 17, 580 (2003).

14. Y. Nomura, A. Sato, S. Sato, H. Mori, and T. Endo, J. Appl. Polym.
Sci., 108, 236 (2008).

15. S. A. Pellice, D. P. Fasce, and R. J. J. Williams, J. Appl. Polym. Sci, 105, 2351 (2007).

16. N. M. Jose, L. A. S. A. Prado, and I. V. P. Yoshida, J. Polym. Sci., Part B: Polym. Phys., 42, 4281 (2004).

17. T. O. Collier, J. M. Anderson, W. G. Brodbeck, T. Barber, and K. E. Healy, J. Biomed. Mater. Res., Part A, 69A, 644 (2004). 